\title{
Recent Advances in Chemically Modified Electrodes, Microfabricated Devices and Injection Systems for the Electrochemical Detection of Heavy Metals: A review
}

\author{
Guo Zhao ${ }^{1,2}$, Hui Wang ${ }^{1,2}$, Gang Liu ${ }^{1,2, *}$ \\ ${ }^{1}$ Key Lab of Modern Precision Agriculture System Integration Research, Ministry of Education of \\ China, China Agricultural University, Beijing 100083 P.R. China \\ ${ }^{2}$ Key Lab of Agricultural Information Acquisition Technology, Ministry of Agricultural of China, \\ China Agricultural University, Beijing 100083 P.R. China \\ *E-mail:pac@cau.edu.cn
}

doi: $10.20964 / 2017.09 .39$

Received: 24 May 2017 / Accepted: 5 July 2017 / Published: 13 August 2017

\begin{abstract}
Heavy metal (HM) ion pollution has become a serious environmental problem in both developed and developing countries and will inevitably pose a threat to humans and ecosystems as a result of HM enrichment in organisms through the food chain. Therefore, HM detection and monitoring are currently attracting increasing attention. However, current analytical methods (based on spectroscopy) to detect HMs are often expensive and tedious and can only be performed by trained personnel. Electrochemical methods for the in situ detection of HMs are some of the most promising alternative methods, featuring easy adaptability, low power costs, short analytical times and high sensitivity. Chemically modified electrodes, which are based on combined electrochemical methods, have been widely used to offset the weaknesses of spectroscopic methods. In this paper, we review different types of materials that have been used to modify electrodes for HM detection. The material characteristics that improved the electrocatalytic activity of the modified surfaces are discussed. Additionally, recent trends in the detection of HMs using electrochemical methods with various types of microfabricated devices and injection analysis systems are highlighted. Finally, the challenges and future perspectives regarding HM determination in real samples using electrochemical methods are critically reviewed, and effective approaches are presented.
\end{abstract}

Keywords: Chemically modified electrodes, electrochemical detection, heavy metal ions, nanomaterials, microfabricated sensors, injection system

$\underline{\text { FULL TEXT }}$ 
(C) 2017 The Authors. Published by ESG (www.electrochemsci.org). This article is an open access article distributed under the terms and conditions of the Creative Commons Attribution license (http://creativecommons.org/licenses/by/4.0/). 